\title{
What affects the presence versus absence of schwa and its duration: A corpus analysis of French connected speech
}

\author{
Audrey Bürki ${ }^{\mathrm{a}), \mathrm{b})}$ \\ Laboratoire de Psycholinguistique Expérimentale, University of Geneva, 40, Bd du Pont d'Arve, 1205 Geneva, \\ Switzerland \\ Mirjam Ernestus \\ Radboud University Nijmegen and Max Planck Institute for Psycholinguistics, P.O. Box 310, \\ 6500 AH Nijmegen, Netherlands \\ Cédric Gendrot and Cécile Fougeron \\ Laboratoire de Phonétique et Phonologie, UMR 7018, CNRS/Sorbonne-Nouvelle, 19, rue des Bernardins, \\ 75005 Paris, France

\begin{abstract}
Ulrich Hans Frauenfelder
Laboratoire de Psycholinguistique Expérimentale, University of Geneva, 40, Bd du Pont d'Arve, 1205 Geneva,
\end{abstract} \\ Switzerland
}

(Received 10 August 2010; revised 3 October 2011; accepted 6 October 2011)

\begin{abstract}
This study presents an analysis of over 4000 tokens of words produced as variants with and without schwa in a French corpus of radio-broadcasted speech. In order to determine which of the many variables mentioned in the literature influence variant choice, 17 predictors were tested in the same analysis. Only five of these variables appeared to condition variant choice. The question of the processing stage, or locus, of this alternation process is also addressed in a comparison of the variables that predict variant choice with the variables that predict the acoustic duration of schwa in variants with schwa. Only two variables predicting variant choice also predict schwa duration. The limited overlap between the predictors for variant choice and for schwa duration, combined with the nature of these variables, suggest that the variants without schwa do not result from a phonetic process of reduction; that is, they are not the endpoint of gradient schwa shortening. Rather, these variants are generated early in the production process, either during phonological encoding or wordform retrieval. These results, based on naturally produced speech, provide a useful complement to on-line production experiments using artificial speech tasks. (C) 2011 Acoustical Society of America. [DOI: 10.1121/1.3658386]
\end{abstract}

PACS number(s): 43.70.Fq, 43.70.Jt [AL]

Pages: $3980-3991$

\section{INTRODUCTION}

The pronunciation of words in connected speech exhibits considerable variation. For decades, researchers have documented such pronunciation variation on the basis of analyses of speech corpora (e.g., Keating, 1998; Malécot, 1976). More recently, researchers have started to take our knowledge of pronunciation variation into account in the construction of psycholinguistic models of speech production and recognition (e.g., Goldinger, 1998; Hawkins, 2003; Ranbom and Connine, 2007). In addition, pronunciation variation is incorporated nowadays in most automatic speech recognition models (see Strik and Cucchiarini, 1999, for a review) and text-to-speech models. Successful incorporation of pronunciation variation in both psycholinguistic and automatic speech processing (ASP) models requires detailed information about the nature of pronunciation variation and its conditioning variables.

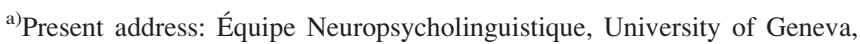
40, Bd du Pont d'Arve, 1205 Geneva, Switzerland.

${ }^{b}$ Author to whom correspondence should be addressed. Electronic mail: audrey.buerki@unige.ch
}

In this study, we focus on one variation process: the so called "schwa-zero alternation" in word-internal position in French. Words affected by this process (hereafter schwa words) can be pronounced either with the schwa (e.g., fenêtre "window" realized as [fənєtR]), or without ([fnєtR]). Variants without schwa are frequent. For instance, in Fougeron et al.'s (2001) corpus of spontaneous speech, $64 \%$ of the schwa words were produced without their schwa.

We will examine schwa alternation in detail by investigating which variables condition the presence versus absence of schwa and the duration of the schwa (when present), using a large corpus of radio-broadcasted speech. Our study has two aims. The first aim is to determine which variables actually influence schwa alternation and schwa duration. Knowledge of these variables can inform linguistic theories. For instance, linguistic theories which assume that the variants without schwa result from a phonological deletion process (e.g., Dell, 1985) need to explain how this phonological process can be sensitive to these variables. Moreover, data on schwa alternation will have implications for ASP. French schwa is an excellent example of a variation process that is difficult to model within ASP: it causes many errors in text- 
to-speech (Lanchantin et al., 2008), in word recognition (Adda-Decker, 2007) or in phonetic alignment (Boula de Mareüil, 2007; Bürki et al., 2008).

Research on the variables governing French schwa alternation is not without precedent. Many studies have investigated the roles of different variables which favor the production of one of the two variants. Some of these studies have been based on data from introspection (Dell, 1985; Fouché, 1959; Grammont, 1914) and others on large databases of recorded speech (Hansen, 1994; Malécot, 1976). With one exception (Racine and Grosjean, 2002), all of these studies considered variables individually, despite the fact that these variables often interact or are correlated. For example, Racine and Grosjean showed that if several variables previously found to affect schwa alternation were combined in a single regression analysis, the influence of some of them vanished. Furthermore, previous studies did not take into account the frequency of the items, so it is possible that the observed influence of some predictors actually resulted from the idiosyncratic behavior of a small number of highly frequent words. Hence, even though many studies have investigated schwa alternation in French, no clear and complete picture has yet emerged of exactly which variables condition the presence of schwa. The analysis that we propose here thus aims to be more rigorous and systematic, and is based on a larger number of tokens. We investigate the contribution of all variables within the same analysis, while eliminating collinearity between them and using conservative significance levels. Finally, we have extended our analysis to include schwa duration and its relation to schwa alternation.

The second aim of this work is to investigate whether corpus studies can be used to go beyond a description of the distribution of pronunciation variants and tell us something about the nature (categorical versus gradient) and locus (the processing stage involved) underlying the production of pronunciation variants. So far, such questions have been addressed mainly by means of on-line experiments (Bagou et al., 2009; Bürki et al., 2010). These experiments have the advantage of producing wellcontrolled linguistic output, but the disadvantage of inducing unnatural production conditions. As a consequence, production experiments cannot investigate pronunciation variation that occurs only in spontaneous speech. More generally, every conclusion based on psycholinguistic experimentation should be validated against speech processing under more natural conditions (i.e., in naturally occurring rather than laboratory-induced speech events).

We will focus on the psycholinguistic question of the level in the production process at which the alternation between the variant with schwa and the variant without schwa is determined. Current models of speech production distinguish several loci. Firstly, schwa may be present in the phonological representation of the word and disappear during the process of phonetic implementation. For instance, as proposed for schwa deletion in English by Levelt (1989), schwa may be absent because the durational parameter for the syllable is set to a minimum, leaving no time for the vowel. Similarly, in the framework of Articulatory Phonology (Browman and Goldstein, 1992), schwa may be absent in the acoustic signal due to the overlapping gestures of the surrounding consonants, as has been claimed by Barnes and Kavitskaya (2002) and Smorodinsky (1998). In this phonetic account, the absence of schwa is the natural result of schwa shortening, and consequently schwa alternation and schwa duration are expected to be influenced by the same variables.

Secondly, schwa alternation may arise as the result of phonological rules, which delete schwa from the (single) phonological representation stored in the mental lexicon (e.g., Dell, 1985), or add schwa (e.g., Côté and Morrison, 2007) during phonological encoding. If schwa alternation is phonological in nature, it is not the natural endpoint of the phonetic process of schwa shortening, and thus it should be affected by different variables from those affecting the duration of this vowel. Phonological accounts of this kind have been largely dominant throughout the long history of the linguistic analysis of schwa in French. Nearly all these accounts are based on data obtained from linguists or their informants via introspection.

Finally, schwa alternation may arise because the mental lexicon contains phonological representations for both the variant with schwa and the variant without schwa. This lexical account is in line with exemplar-based and hybrid production theories (e.g., Bybee, 2001; Pierrehumbert, 2001). In a recent series of on-line production experiments, Bürki et al. (2010) provided evidence supporting the lexical account for French schwa alternation. They showed that participants produce a given variant for a word (i.e., the variant with schwa or the variant without schwa) more quickly the higher its frequency of occurrence compared to the other variant. Apparently, speakers have stored the relative frequencies of the different pronunciation variants of a word in their lexicon, which suggests that these pronunciation variants are themselves stored. If this lexical account is correct, the absence of schwa is again not just the result of extreme schwa shortening, and schwa alternation and schwa duration may show sensitivity to different conditioning variables.

In light of the accounts described above, we address the question of the locus of schwa alternation in French by comparing the variables that predict the realization of variants with and without schwa (schwa alternation) and that affect the duration of schwa in the variants with schwa (schwa duration). If schwa alternation and schwa duration arise as the result of the same phonetic process, they should be affected by (almost) the same sets of variables. If, in contrast, the processes governing schwa alternation and schwa duration have different loci, they should be affected by different sets of variables.

\section{MATERIALS}

We first created a list containing all 18553 French morphologically simple and complex words (excluding compounds) with an internal schwa (hence excluding clitics and polysyllabic words with a schwa in their last syllable) that 
occurred in four lexical databases: Lexique (New et al., 2001), Brulex (Content et al., 1990), ILPho (Boula de Mareüil et al., 2000), and Grand Robert Dictionary. We then extracted all tokens of these words from the subset of the ESTER corpus ( $24 \mathrm{~h}$ of radio-broadcasted news produced by 574 speakers, Galliano et al., 2005) for which the Institut de Recherche en Informatique et Systèmes Aléatoires (IRISA) automatic speech alignment system had produced a phonetic transcription aligned with the acoustic signal at the word and phoneme levels. This phonetic transcription is based on the orthographic transcription, a pronunciation dictionary containing two pronunciation variants for schwa words (the ILPho dictionary, Boula de Mareüil et al., 2000), and 35 context independent phone models, represented by threestates Hidden Markov Models (with a total of 114 states with 128 Gaussians per state for each model).

We retained only words that contained alternating schwa and that were represented by at least a total of five tokens. This resulted in a dataset of 5016 tokens. We decided that a given word contained an alternating schwa if the IRISA system designated some tokens as pronunciation variants with schwa and others without schwa.

The automatic transcription and segmentation of these tokens were manually corrected by the first author. We used periodicity in the signal and the appearance/disappearance of the second formant to define the presence, onsets, and offsets of the schwa vowels. To evaluate the reliability of the manual segmentation, the third author corrected a subset of the data (47\%), having access to the first judge's corrections. Inter-judge agreement on the presence of schwa was assessed using Cohen's kappa coefficient (Cohen, 1968). This coefficient reached 0.98 , indicating an "almost perfect agreement" according to Landis and Koch (1967). With respect to the segment boundaries, $5 \%$ of them showed a difference above $10 \mathrm{~ms}$ between the two manual corrections, and $1 \%$ a difference above $20 \mathrm{~ms}$. For further analyses, we used only the corrected segmentations from the first judge.

Finally, we excluded from this dataset all words that, after manual correction, were produced with only one pronunciation (i.e., all occurrences produced either with schwa or without, and thus not containing an alternating schwa according to our definition). We also excluded words that had been labeled as schwa words in the automatic transcription but were not, and also tokens that were produced by speakers with non-native accents. Whether a given speaker had a native or non-native accent was evaluated on the basis of perceptual information by the first author. The final data set contained a total of 4294 tokens representing 183 word types (124 with the schwa in the initial syllable and 59 with the schwa in the second syllable), produced by 361 different speakers. Of these 4294 tokens, 1198 were realized without schwa and 3096 were realized with schwa.

\section{VARIABLES}

In the following subsection we will discuss the 17 variables whose predictive values for schwa alternation and vowel duration were tested. They are summarized in Table II. Unfortunately, we could not test all variables described in the literature because of the lack of data (our 4294 tokens appeared insufficient). However, we were able to include most of them, and, importantly, the ones whose effects have been reported more than once in the literature.

\section{A. Segmental and phonotactic variables}

The absence of schwa always leads to a consonant sequence. Several segmental and phonotactic properties of this sequence have been claimed to influence schwa alternation. First, schwa is less often absent if the resulting consonant sequence contains more than two consonants ("loi des trois consonnes" of Grammont, 1914). Secondly, differences in the articulation of the two consonants surrounding the schwa influence schwa alternation. Authors have used different terms and scales to describe these differences. For instance, Malécot (1976) claimed that there is an effect of the consonants' degrees of constriction (i.e., aperture in Malécot's terms). Relying on the scale $p t k b d<f s \int v z Z<l R$ $N<w j$, he found that schwa was more likely to be absent if the two consonants differed in their degree of constriction, especially if the second consonant was less open than the first. Several other authors claim that the relation in sonority between the consonants is relevant: ascending sonority favors the absence of schwa (Côté, 2000; Côté, 2009; Hansen, 1994). Finally, distributional factors influence schwa alternation: schwa is less often absent if the resulting consonant sequence does not exist or is rare in French (Léon, 1971).

The nature of the preceding consonant also influences schwa alternation. For instance, Walker (1996) observed that schwa words tend to be always produced with their schwa when the schwa is preceded by $/ \mathrm{t}, \mathrm{k}, \mathrm{b}, \mathrm{g}, \mathrm{v}, \mathrm{l}$, or $\mathrm{m} /$, and to be produced with both the schwa and the non-schwa variants when the schwa is preceded by $/ \mathrm{s}, \int Z$, $\mathrm{R}$ or $\mathrm{n} /$. He interprets his observations in historical terms, and suggests that words from the first category are becoming stable (non-alternating). Similarly, for Montreal French, Côté (2009) reported that obstruent-schwa-obstruent and obstruent-schwa-nasal sequences tend to be produced exclusively without schwa if the initial consonant is a fricative, but both with and without schwa if the initial consonant is an oral stop. Finally, Hansen (1994) found that schwa is seldom absent in words starting with /Rə/ (e.g., redire "say again").

Vowel duration, in contrast, appears to be especially affected by the properties of the following consonant. Vowels tend to be longer before voiced than before voiceless consonants (e.g., O'shaughnessy, 1981), before fricatives than plosives (e.g., Delattre, 1964), and before more posterior consonants (e.g., Delattre, 1962; Di Cristo, 1985). In addition, vowels tend to be shorter before a liquid followed by another consonant than before a liquid alone (O'shaughnessy, 1981). Some studies suggest that several characteristics of the following consonant may interact (e.g., Di Cristo, 1985).

Several authors also mention an effect of the prevocalic consonant on the duration of the vowel. Vowels are longer after voiced consonants (Di Cristo, 1985) and after plosives (compared to fricatives, O'shaughnessy, 1981, see also 
Thilly, 1993). According to Thilly, the place of articulation of a preceding fricative also plays a role.

Given these prior reports, we investigated the following variables describing the properties of the surrounding consonants: following and preceding consonant voicing ${ }^{1}$ (voiceless versus voiced consonants, i.e., voiced obstruents, liquids and nasals), following and preceding consonant manner of articulation (fricative; plosive; liquid; and nasal) and following and preceding consonant place of articulation: front consonants (i.e., labial), mid consonants (i.e., alveolar and post-alveolar), and posterior consonants (i.e., velar and uvular). Table I lists the number of tokens in each level of these three variables for following and preceding consonants. We also included a categorical variable coding whether the word started with "re" (1026 tokens in "re").

We also chose several variables to describe the nature of the consonant sequence when the schwa is absent. We coded (a) the number of consonants (we considered glides as consonants) using two different measures. For the first one, the number of consonants in the sequence is computed within the schwa word; there were 3808 tokens with a twoconsonant sequence (e.g., /mz/ as in mesure "measure") and 486 tokens with a three-consonant sequence (e.g., /skR/ as in secrétaire "secretary"). The second measure took into account the number of consonants in the sequence, including the final consonants of the previous word, if any. There were 3151 tokens with a two-consonant sequence (e.g., /sm/ as in la semaine "the week") and 1138 tokens with three or more consonants (e.g., /tsm/ as in cette semaine "this week"). We also coded (b) whether the consonant sequence respects the sonority principle (2298 tokens) or not (1996 tokens). The sonority principle was respected if the consonant sequence had an ascending sonority. In order to compute this variable, we used different scales: a scale with three levels (fricatives and stops $<$ nasals $<$ liquids, e.g., Clements, 1990, Côté, 2004), a scale with four levels, (stops $<$ fricatives $<$ nasals $<$ liquids, e.g., Côté, 2009), and a scale with six levels (voiceless stops $<$ voiced stops $<$ voiceless fricatives $<$ voiced fricatives $<$ nasals $<$ liquids). We also took into account (c) whether the resulting consonant sequence exists in French by means of a categorical variable with three levels: the sequence does not exist and the consonants are always separated by a vowel word internally (560 tokens, e.g., /ds/ as in dessous "under"); the sequence is a possible onset cluster (580 tokens, e.g., /pl/ as in appeler "call," which occurs in words like plier "to fold"); the sequence exists but is always heterosyllabic (3154 tokens, e.g., /R.s/ as in reçu "receipt," which occurs in words like verser "to pour"). Finally, we included (d) the cumulated token frequency of French words containing the conso- nant sequence in any position in the word (according to Crouzet, 2000).

\section{B. Morphological and grammatical variables}

In some words, schwa occurs morpheme-internally (e.g., fenêtre "window"), while in others they occur at morpheme boundaries (e.g., naturellement "naturally"). Hansen (1994) compared deletion rates between these two types of schwa and found no statistically significant difference. However, she considered the morphological complexity of a word to be a categorical property (a word is either morphologically simple or complex), while recent studies suggest that morphological complexity may be of a more gradient nature (e.g., Hay, 2003). The question thus arises whether a gradient variable of morphological complexity plays a role in schwa alternation and schwa duration.

In order to take the gradient nature of morphological complexity into account in our analyses, we had five native speakers of French with a good knowledge of morphology judge the morphological complexity of each word, on a five-point scale, by indicating whether the schwa was morpheme-internal (value 1) or clearly at a morpheme boundary (value 5). Analysis of the responses showed that the whole scale was used, but the distribution of the responses was right skewed: mode and median were equal to 1 for all judges. Overall mean for the different judges ranged from 1.5 to 2.3 and overall mean for the different words ranged from 1 to 5 . While some words (e.g., chemin "way") received similar ratings from all participants (including unanimous judgments for 56 words, i.e., all participants selected the same value on the scale for these words), ratings for some of the others were rather heterogeneous (e.g., r $\underline{\underline{e}-}$ cherche "research"). We took the mean value averaged over judges for each word as the variable representing the morphological complexity of the schwa words.

In addition, we investigated the role of the grammatical class of a word. To our knowledge, no study has reported an influence of this variable on word-internal schwa alternation. By contrast, several studies have shown an effect on vowel duration: vowels are more prone to temporal reduction in function words than in content words (e.g., Bell et al., 2009; Van Bael et al., 2007). We included a binary variable coding word class (function word versus content word). Function words included prepositions (548 tokens, e.g., depuis "since"), pronouns (239 tokens, e.g., lequel "which") and conjunctions (41 tokens, e.g., cependant "yet"). Content words included verbs (1491 tokens, e.g., re $\underline{\text { dire }}$ "to say again"), nouns (1255 tokens, e.g., avenir "future"), adverbs (380 tokens e.g., maintenant "now") and adjectives (283 tokens, e.g., petit "small").

TABLE I. Distribution of tokens according to the properties of the consonant preceding or following the schwa.

\begin{tabular}{|c|c|c|c|c|c|c|c|c|c|}
\hline & \multicolumn{2}{|c|}{ Voicing } & \multicolumn{4}{|c|}{ Manner of articulation } & \multicolumn{3}{|c|}{ Place of articulation } \\
\hline & Voiced & Voiceless & Fricative & Plosive & Liquid & Nasal & Front & Mid & Posterior \\
\hline Following consonant & 2905 & 1389 & 705 & 1323 & 1031 & 1235 & 1527 & 1975 & 792 \\
\hline Previous consonant & 2523 & 1771 & 1513 & 1479 & 1117 & 185 & 822 & 2447 & 1025 \\
\hline
\end{tabular}




\section{Prosodic variables}

Several prosodic variables have been found to influence both schwa alternation and vowel duration. First, schwa alternation and vowel duration are said to vary according to the position of the syllable in the prosodic word. Schwas are more often realized in the first syllable (Dell, 1985; Hansen, 1994; Malécot, 1977) than in internal syllables and all vowels are longer in word-initial syllables than in word-internal syllables (e.g., Crompton, 1980), while they are the longest in word final syllables (e.g., Klatt, 1975; O'shaughnessy, 1981). We therefore classified schwa according to its position in the word: initial (i.e., schwa in the first syllable, 3566 tokens, e.g., fenêtre "window") versus non-initial (728 tokens, e.g., toutefois "nevertheless"). Note that we did not consider schwa occurring in word final syllables in the present study.

Second, the position of the word in the utterance seems to influence schwa alternation and vowel duration. Schwas are more often realized in initial positions (Malécot, 1976) and vowels tend to be longer at the end of utterances (e.g., Klatt, 1976; Oller, 1973). Accordingly, we coded word position in the utterance as utterance-initial (i.e., first word of the utterance, 550 tokens, e.g., Demain matin la... "Tomorrow morning the ..."), utterance-internal (2863 tokens, e.g., ... doit ouvrir demain une ... “... will open tomorrow a ..."), utterance-final (i.e., in the last word of the utterance, 742 tokens, e.g., ... repoussée à demain. “...postponed until tomorrow."), or as words produced in isolation (i.e., in a single word utterance, 139 tokens, e.g., Bienvenue "Welcome"). Utterance boundaries were annotated manually by independent transcribers in the ESTER project (e.g., Galliano et al., 2005). The following criteria guided the transcriptions. Changes in speakers and silences over $0.5 \mathrm{~s}$ were taken as utterance boundaries. Stretches of discourse longer than $15 \mathrm{~s}$ were cut in smaller utterances, according to syntactic and semantic criteria (these criteria were chosen by the transcribers themselves). In addition, we considered transcribed filled pauses over $0.5 \mathrm{~s}$ as marking an utterance boundary.

Third, word length has been found to affect both schwa alternation and segment duration: the longer a word, the more likely it is to be pronounced without its schwa (Léon, 1971) and the shorter its segments (e.g., Crystal and House, 1990; Adda-Decker et al., 2008, for French). In our analyses, we considered two measures of word length: number of phonemes and number of syllables of the schwa variant.

\section{Speech rate variable}

Speech rate has been reported to affect schwa alternation and duration: a higher speech rate is associated with a higher proportion of non-schwa variants (Grammont, 1914; Hansen, 1994; Malécot, 1976, 1977) and with shorter vowels (e.g., Gopal, 1990; Klatt, 1976).

We defined speech rate as the number of syllables in the sequence consisting of the two words preceding the target word, the target word itself, plus the two words following, divided by the acoustic duration of this sequence. If there was a pause in this five-word sequence, the word(s) preceding or following this pause (depending on whether the pause was before or after the target word) was/were not taken into account.

\section{E. Speaker variable}

Speakers' realization of schwa words has also been found to vary according to various sociolinguistic variables. First, the average proportion of non-schwa variants varies among regiolects. Schwas tend to be present more often in standard than in some regional varieties of French (e.g., Québec French, see Côté, 2008) but are especially frequent in southern French (Durand and Eychenne, 2004; Eychenne, 2006; Léon, 2005). Second, younger speakers tend to produce schwas less often than more elderly speakers (Hansen, 1994; Léon and Tennant, 1988; Malécot, 1976). Unfortunately, our database does not contain detailed information about the different speakers. However, in order to account for speaker differences, we included Speaker as a random variable in our multi-level regression analysis (see Sec. IV A). This random variable also allows us to generalize our results to speakers not included in the data set.

\section{F. Lexical variable}

Words differ in how often they are produced with and without schwa. Racine and Grosjean (2002) showed that French speakers can reliably estimate the frequencies of the two variants for a given word. Racine (2007) asked two groups of 12 speakers (from the north-western part of France and from Switzerland) to rate on a seven-point scale how often each of 2289 nouns occur with and without wordinternal schwa. The thus-obtained ratings correlate well with the frequencies with which these words occur with and without schwa in a corpus of retold stories $(r=0.47)$. Interestingly, Racine and Grosjean also observed a positive correlation between the frequency with which schwa was realized for a given word in this corpus and the mean duration of schwa in that word.

Racine's (2007) frequency ratings of pronunciation variants with and without schwa were available for most nouns in our data set (1093 tokens, 60 word types produced by 218 speakers). In the present study, we only examined the role of the ratings provided by the Swiss participants, since the French participants showed very little variation in their ratings and their ratings do not show a normal distribution.

\section{G. Word predictability variables}

Several studies, mostly based on languages other than French, have shown that the more predictable the occurrence of a word is, the more likely it is to be temporally reduced (e.g., Bell et al., 2003; Pluymaekers et al., 2005; Scarborough, 2011; and for French: Torreira and Ernestus, 2009). In line with segment deletion in Germanic languages, French schwa has been found to be more often absent in high than in low frequency words (Hansen, 1994; Racine and Grosjean, 2002). Note, however, that Fougeron et al. (2001) found no effect of lexical frequency on schwa alternation in their corpus of spontaneous speech. So far, no study has reported an influence of word predictability measures on vowel duration in French. 
TABLE II. Explanatory variables considered in the present study.

\begin{tabular}{|c|c|}
\hline Variable & Description \\
\hline Segmental variables & $\begin{array}{l}\text { - Following and preceding consonant } \\
\text { voicing } \\
\text { - Following and preceding consonant man- } \\
\text { ner of articulation } \\
\text { - Following and preceding consonant place } \\
\text { of articulation } \\
\text { - Whether word starts with "re" }\end{array}$ \\
\hline Phonotactic variables & $\begin{array}{l}\text { - Number of consonants in sequence } \\
\text { - Respect of sonority principle } \\
\text { - Existence of consonant sequence } \\
\text { - Consonant sequence token frequency }\end{array}$ \\
\hline $\begin{array}{l}\text { Morphological/grammatical } \\
\text { variables }\end{array}$ & $\begin{array}{l}\text { - Morphological composition } \\
\text { - Word class }\end{array}$ \\
\hline Prosodic variables & $\begin{array}{l}\text { - Word position in utterance } \\
\text { - Schwa position in word } \\
\text { - Word length (number of phonemes and } \\
\text { number of syllables) }\end{array}$ \\
\hline Speech rate variable & $\begin{array}{l}\text { - Number of syllables in two preceding } \\
\text { words }+ \text { target word }+ \text { two following words/ } \\
\text { total acoustic duration of this sequence }\end{array}$ \\
\hline Speaker variable & - Random variable \\
\hline Lexical variable & - Phonological variant frequency \\
\hline Word predictability variables & $\begin{array}{l}\text { - Lexical frequency (Lexique and ESTER) } \\
\text { - Backward and Forward mutual information }\end{array}$ \\
\hline
\end{tabular}

We investigated the influence of four predictability measures. The first two measures indicate the word's a priori probability. They are the word's lexical frequency as given by the French database Lexique (New et al., 2001) and in the ESTER corpus, that is, in the same corpus as from where we extracted our materials. We took the logarithms of these frequencies. The two resulting lexical frequency measures are highly correlated $(r=0.71$ with 0.69 and $0.7295 \%$ confidence intervals, $p<0.0001)$.

The third and fourth predictability measures are entropies indicating the word's probability given either the preceding or the following word (forward and back mutual information, respectively). These measures have been shown to predict reduction degree in Germanic languages (Bell et al., 2003; Jurafsky et al., 2001; Kuperman et al., 2007) and are computed as follows (X and Y correspond either to the previous word and the target word or to the target word and the following word, and frequencies are taken from the ESTER corpus):

$$
M I(X ; Y)=\log \frac{(\text { Frequency }(X Y))}{(\text { Frequency }(X))^{*}(\text { Frequency }(Y))} .
$$

\section{RESULTS}

\section{A. Statistical analysis}

In order to investigate the roles of the variables mentioned above on schwa alternation and duration we used (generalized) linear mixed effects models with speaker and word as crossed random effects and with contrast coding
(Baayen et al., 2008; Pinheiro and Bates, 2000). Each model was built using a stepwise procedure. We included the different predictors in the model sequentially and retained only those contributing significantly to the model $(p<0.01)$. Predictors showing collinearity were orthogonalized if one of the predictors was continuous. In such cases, we ran a linear model with the continuous variable as the response and the variables correlated with this continuous variable as predictors, and used the residuals of this linear model instead of the raw values of the continuous variable. If the predictors showing collinearity were all categorical variables, we built separate models, each containing only one of the factors involved in the collinearity, and we chose the best model using Akaike Information Criterion (AIC) and Bayesian Information Criterion (BIC). We tested interactions between variables whenever possible. ${ }^{2}$ Statistical computations were conducted with the software R (R Development Core Team, 2011) including the package lme4 (Bates and Sarkar, 2007).

\section{B. Predictors of schwa alternation}

We fitted several generalized linear mixed effects models with a logit link function to account for schwa alternation. In all analyses, the dependent variable indicated the presence versus absence of schwa. The first analysis predicted schwa alternation in all 4294 word tokens. It took into account all variables except back and forward mutual information as they were not available for many tokens.

\section{All tokens}

The final model based on all tokens in the data set predicted $90 \%$ of the observations. Inclusion of the random terms was supported by likelihood ratio tests (speaker: $\chi^{2}(1)=82.2, p<0.0001$; word: $\left.\chi^{2}(1)=443.1, p<0.0001\right)$.

Table III gives the statistical values associated with each of the significant fixed predictors and interactions. There are four significant main effects: position in the word, position in the utterance, speech rate, and respect of the sonority principle. Schwa was more often present in wordinitial than in non-initial syllables (in $82 \%$ of the initial syllables versus in $22 \%$ of the non-initial syllables) and in utterance-initial position than in utterance-medial or utterance-final position, and in utterance-medial than in utterance-final position (in $85 \%$ of the utterance initial syllables, in $71 \%$ of the medial syllables, and in $68 \%$ of the final syllables). We did not find a difference between words produced in isolation and words in sentences, probably because of the small number of tokens produced in isolation. Schwa was also more often present at lower speech rates $(\beta=585.1)$ and if the consonant sequence that would result from the absence of schwa did not obey the sonority principle, that is, if the consonants surrounding schwa were of descending sonority according to a six-level scale $(87 \%$ of the schwa were present when the sonority principle was not obeyed, versus $59 \%$ when it was obeyed). Note that all three scales of sonority tested (see Sec. III A) influenced the presence versus absence of schwa. Comparisons of the models run with each of these scales revealed that the scales involving four and six levels did not differ from each other, and 
TABLE III. Summary of Mixed Effects Model for variables predicting schwa alternation.

\begin{tabular}{lcrc}
\hline \hline Predictor & Df & F & p \\
\hline Schwa position in word & 1,4137 & 119.25 & $<0.0001$ \\
Word position in utterance & 3,4137 & 23.41 & $<0.0001$ \\
Speech rate & 1,4137 & 231.80 & $<0.0001$ \\
Respect of sonority principle & 1,4137 & 8.23 & $<0.01$ \\
Number of consonants in sequence & 1,4137 & 4.95 & $<0.05$ \\
Number of consonants in sequence by & 1,4137 & 9.60 & $<0.01$ \\
Respect of sonority principle & & & \\
\hline \hline
\end{tabular}

better explained the data than the three-level scale. In addition, there was a two-way interaction between respect of the sonority principle and number of consonants in the resulting consonant sequence when computed within the word. The sonority principle only affected words for which the absence of schwa would have resulted in a sequence of two consonants. For tokens that would then have had a two-consonant sequence of increasing sonority (i.e., a sequence that obeys the sonority principle), $57 \%$ of schwa were present, while for tokens that would then have had a two consonant sequence of decreasing sonority (i.e., a sequence that violates the sonority principle) $87 \%$ of schwa were present. For words that would then have contained sequences of three consonants, the sonority relationship of the two consonants surrounding schwa was not important, and the presence of schwa was favored independently of whether the sequence obeyed ( $86 \%$ of schwa present) or violated $(90 \%$ of schwa present) the sonority principle on the basis of the six-level scale.

The number of consonants in the sequence resulting from the absence of schwa computed on the basis of the target and previous words did not have a statistically significant effect and did not interact with the sonority principle. In order to further investigate the role of the number of consonants at the end of the previous word, we conducted an additional analysis. We restricted the dataset to the schwa words which did not occur in isolation, after a pause, or at the beginning of an utterance, and had a schwa in the initial syllable of their full form $(N=3065)$. We examined whether the presence of schwa in these words was influenced by whether the previous word ended with a vowel (i.e., the schwa is preceded by one consonant only) or with one or more consonant(s) (i.e., the schwa is preceded by at least two consonants). We found no effect of this predictor and no interaction with the sonority principle $(p>0.1)$ : schwa words preceded by a vowel were produced in their nonschwa variant as frequently as schwa words preceded by a consonant ( $81 \%$ versus $80 \%$ of schwa present).

The random effects in the model showed that speakers varied in their sensitivity to the sonority principle and to the position of schwa in the word. The model with these two added random terms (i.e., sonority principle and position of schwa in the word) was better than a model with only random intercepts for speakers and words $\left(\chi^{2}(5)=48.7\right.$, $p<0.0001)$. Words appeared not to vary in their sensitivity to any of the predictors.

\section{Sub-analysis for mutual information}

Mutual information with the preceding and following word could only be computed for words directly preceded or followed by other words. We restricted the data set to the 3586 word tokens not occurring after a transcribed silence, whatever its duration, for testing the role of back mutual information and to the 3395 tokens not occurring before a silence for testing the role of forward mutual information. These two predictability measures showed normal distributions ranging from -14.85 to 0 (back mutual information) and -14.57 to 0 (forward mutual information). We added these two predictors to the model described in Sec. IV B, but none of them reached significance. Our data thus did not show any evidence that the probability of a schwa word given the preceding or following word influenced schwa alternation.

\section{Predictors of schwa duration}

We investigated schwa duration in four different analyses using linear mixed effects models. The first analysis predicted schwa duration in all 3096 word tokens realized with schwa and only took into account variables that were available for most tokens (see the following analyses for the remaining variables).

\section{All tokens produced with schwa}

Schwa duration in the 3096 word tokens ranged from 8 to $150 \mathrm{~ms}$, with a mean of $51 \mathrm{~ms}(\mathrm{sd}=18)$ and a median of $50 \mathrm{~ms}$. Duration was (natural) log transformed in order to reduce the skewness in the distribution and therefore the likelihood that the results would be distorted by outliers. Again, we considered speaker and word as crossed random effects and followed the stepwise procedure described above. For the final model, 66 data points fell outside the range of -2.5 to 2.5 units of standard deviation of the residual error. They were removed and the model was rerun without these outliers.

The model (see Table IV) showed two statistically significant main effects and three significant interactions. Together they showed that schwa was shorter (1) at higher speech rates, especially if followed by a voiced consonant; (2) if schwa was not in a word-initial syllable, especially if preceded by a voiced obstruent; and (3) if schwa was surrounded by voiceless obstruents.

Furthermore, the random effect part of the model showed that speakers varied in their sensitivity to the position of schwa in the word. The model with this added random term and a random term for word was better than a model with just random intercepts for speakers and words $\left(\chi^{2}(2)=35.0, p<0.0001\right)$. Words appeared not to vary in their sensitivity to any of the predictors.

\section{The role of mutual information}

We investigated the effects of mutual information with the previous word and with the following word for those tokens that were directly preceded or followed by another word (2527 and 2463 tokens, respectively). These two predictors showed a normal distribution ranging from 
TABLE IV. Summary of Mixed Effects Model for variables predicting schwa duration.

\begin{tabular}{lrrr}
\hline \hline Predictor & Df & F & P \\
\hline Schwa position in word & 1,2909 & 21.60 & $<0.0001$ \\
Speech rate & 1,2909 & 359.45 & $<0.0001$ \\
Following consonant voicing & 1,2909 & 7.82 & $<0.01$ (N.S) $^{\mathrm{a}}$ \\
Preceding consonant voicing & 1,2909 & 4.72 & $>0.01$ \\
Following consonant voicing by & 1,2909 & 16.48 & $<0.0001$ \\
preceding consonant voicing & & & \\
Speech rate by following consonant voicing & 1,2909 & 13.15 & $<0.001$ \\
Position by preceding consonant voicing & 1,2909 & 7.43 & 0.01 \\
\hline
\end{tabular}

${ }^{\mathrm{a}}$ The value for the parameter does not differ from 0 .

-14.85 to 0 (back mutual information) and from -14.57 to 0 (forward mutual information). We added these two variables separately to the final model for schwa duration described above. Back mutual information appeared significant $(F(1,2408)=6.66, p<0.05)$. The higher the predictability of the word given the following word was, the shorter the duration of schwa observed (see Fig. 1, left panel).

\section{The role of variant frequency}

We investigated the potential effect of the frequency with which schwa was rated to be absent for the given word by Racine's (2007) Swiss participants. We restricted ourselves to those words for which these rates were available (see Sec. III F.). We added this new predictor to the main effects of the final model for duration (see Sec. C 1). The interaction between the sonority of the preceding and following consonants was no longer significant and was therefore removed from the statistical model. Variant frequency contributed significantly to the model $(F(1,1059)=13.40$, $p<0.001)$ as illustrated in Fig. 1. Words estimated to be more frequent in their schwa variants tended to have longer schwas.

\section{GENERAL DISCUSSION}

The first aim of the present study was to determine which of the many variables mentioned in the literature influenced the presence/absence of word-internal schwa in a corpus of connected French. We analyzed more than 4000 tokens of 183 schwa words extracted from a large corpus of radiobroadcast news.

Firstly, our analyses demonstrated the influence of only a relatively small number of predictors (five) despite the large number of data points (4294). Our results showed that the pronunciation of variants with or without schwa in this corpus was influenced by speech rate, schwa position in the word, word position in the utterance, number of consonants in the consonant sequence, and respect of the sonority principle in this sequence. The literature, in contrast, makes claims based on over 20 variables, often on the basis of much smaller data sets. This discrepancy probably results from a difference in testing methods, ours being more rigorous and systematic. First, we investigated the contribution of every predictor, given the contributions of all other predictors. Moreover, special care was taken to eliminate collinearity

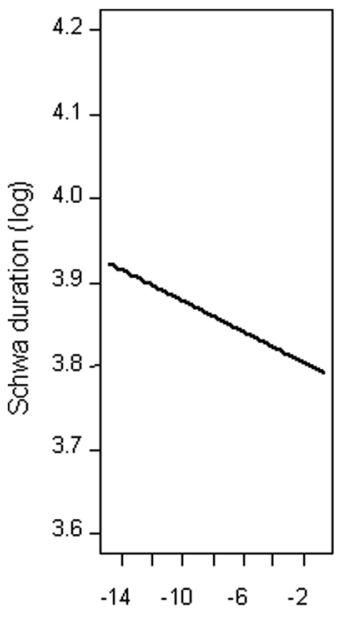

Back mutual information

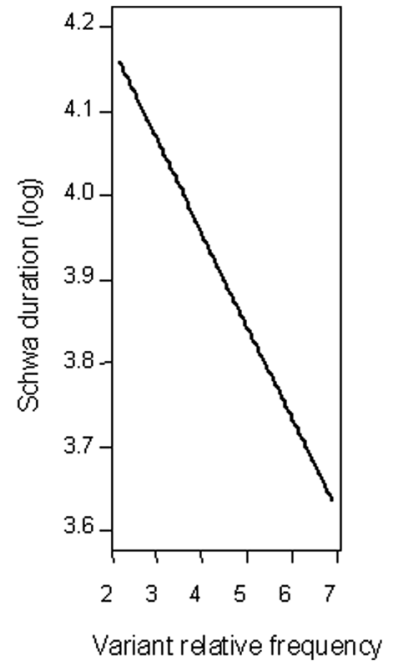

FIG. 1. Schwa duration as a function of back mutual information (left) and variant frequency (right) as predicted by the statistical models.

between predictors. By contrast, most previous research tested each predictor individually, and consequently the influence observed for some variables may have resulted from their strong correlation with other, more influential variables. Furthermore, we used a conservative alpha level $(0.01)$ in order to rule out the possibility that some predictors appeared to be significant just by chance. Finally, the inclusion of random effects for word and speaker may have made the effects of some predictors disappear. This can be exemplified by lexical frequency. Lexical frequency did not surface as a significant predictor at all in our data. However, if our statistical model is run without the random term for word, lexical frequency is highly significant, which is in line with several previous studies (Hansen, 1994; Racine and Grosjean, 2002). This suggests that there is no effect of lexical frequency on schwa alternation and that its apparent effect is simply attributable to the behavior of some specific (high frequency) words.

Secondly, our results showed large differences among speakers. Several studies have mentioned such differences and related them to the speakers' ages or regional backgrounds (Hansen, 1994; Léon and Tennant, 1988; Malécot, 1976). Our data showed that speakers did not only differ in how often they produced variants with or without schwa but also in their sensitivity to some variables: the position of schwa in the word and the sonority principle did not affect all speakers' behavior.

Thirdly, these data provided more information on two variables that have been repeatedly argued to influence schwa alternation with zero. One variable represents the number of consonants in the resulting cluster. Our data showed that this variable best explains the presence of schwa in our corpus if it is computed within the word and not across words. This result contrasts with the analysis of Côté (2009), who found an effect of the size of the consonant sequence comprising the final consonants of the preceding word. Our findings call for further investigation, but we can propose at least three post hoc explanations. According to the first, the number of consonants at the end of a given 
word only influences the presence of schwa in the following word when the two words form a phonological unit. We are referring here to sequences that potentially form a phonological word such as "determiner + noun" sequences. Unfortunately, the relationship between the test word and the preceding word was not controlled in our data. Another possibility is that the number of consonants in the resulting cluster of a given word is a better predictor of the presence of schwa because it does not vary per word token. For instance, words with resulting clusters of two consonants will be produced more often overall in their reduced variants than in their schwa variants, independently of the preceding word. This characteristic is thus a characteristic of the word itself and can be stored in its lexical representation. As a consequence, it may have a stronger effect than a characteristic that is context-dependent. According to a third explanation, this result is specific to the speech style considered in the present study. Accordingly, the final segment of the preceding word may affect the realization of words with a schwa in their initial syllable in some speech styles, including conversational speech, but does not influence the realization of these words in journalistic speech.

Our data allow us to also better characterize the variable "respect of the sonority principle." Several sonority scales are described in the literature. In the present study, we found that the two scales which attributed a different sonority to fricatives and stops better explained the presence of schwa than a scale which grouped the obstruents (see Côté, 2009, for a similar conclusion for Canadian French).

These results help constrain linguistic and psycholinguistic theories. Most linguistic theories predicting the presence versus absence of schwa refer to only a subset of our variables, including the phonotactic properties of the consonant sequence formed by schwa's surrounding consonants, and the position of schwa in the word (e.g., Charette, 1991; Dell, 1985; Lyche and Durand, 1996). Our data suggest that better description accuracy could be achieved if speech rate and the position of the word in the utterance were systematically included in these models. Psycholinguistic models of word production must also be able to explain the influences of the five variables which we documented. For instance, models which assume that both the schwa and the nonschwa variants are stored in the mental lexicon have to specify the mechanisms and time course underlying the influence of variables such as speech rate and word position in the utterance. In addition, both phonological theories and psycholinguistic models should offer an explanation of exactly how the different variables combine to influence the probability of variants with versus without schwa in connected speech.

Our results also have practical implications. They can be used to improve the performance of speech recognition systems. As mentioned above, schwa alternation often leads to recognition errors. In order to reduce such errors, some studies have included two variants for a subset of words in the pronunciation lexicon, following very approximate rules. Boula de Mareüil and Adda-Decker (2002), for example, applied a within-word three-consonant rule: schwa in a given word is defined as optional (and the word consequently has two variants in the lexicon) if its absence results in a twoconsonant sequence, and obligatory (hence the word has only the variant with schwa in the lexicon) if its absence results in a three-consonant sequence. Our results confirm that such a rule is too simplistic and show which additional variables should be taken into account. The influence of at least two additional predictors that we have shown to be important in predicting schwa alternation can be easily implemented in automatic recognition systems: the respect of the sonority principle, modulated by the number of consonants in the resulting cluster, and position of the schwa in the word. On the basis of these three variables, the a priori probability of each variant for each schwa word can be determined, which can be used to modulate the probability that the system selects the variant for recognition. Further gains could be made by dynamic adjustment of the selection probability of each variant according to speech rate and word position in the utterance. Several automatic speech recognition systems already use information on speech rate to increase recognition accuracy (see e.g., Wrede, 2002, for a review). In such systems, information about speech rate could be used, along with acoustic information, to facilitate the selection of the more appropriate variant.

Another potential application of our results concerns textto-speech synthesis systems. Most text-to-speech systems produce only one single phonetic realization for a given word or sequence. Some of these systems apply very simple linguistic rules that determine which of the two variants of a schwa word is always produced. In Boula de Mareüil (2007), for instance, non-final schwa is always realized except in a few words or consonantal contexts. These systems thus do not take into account that the probability of a pronunciation variant also depends on contextual factors. Our results suggest that this may lead to artificial outputs. Text-to-speech synthesis could become more natural if two variants for each word were incorporated in the systems and the likelihood of each variant was based on the segmental make-up of the word (position of schwa in the word, number of consonants surrounding the schwa, respect of the sonority principle in that consonant sequence), its position in the utterance, and speech rate.

A question for future research concerns the extent to which the results of the present research can be generalized to other speech styles. Whereas journalistic speech is certainly more natural than speech elicited in the laboratory, it differs from conversational speech in many respects. It is more formal and contains parts of prepared speech, which are probably more similar to read speech than to conversational speech. As a consequence, we may expect that journalistic speech contains fewer non-schwa variants than everyday conversations. An interesting goal for further studies would be to examine further whether and how the sets of variables that influence the presence/absence of schwa and its duration differ among speech styles.

The second aim of the present study was to examine whether analyses of a large corpus of connected speech could provide information about the nature (gradient versus categorical) and locus (processing stage) of an alternation process. So far, the few studies addressing these issues have been based mainly on on-line production experiments. 
Psycholinguistic experiments, however, cannot be used to investigate all types of pronunciation variation, since some types only occur in spontaneous casual speech. Moreover, during on-line production experiments speakers may demonstrate somewhat unnatural speech behavior, while speech elicited in non-experimental conditions is likely to be more natural.

In order to address the question of the locus of schwa alternation in French during the production process, we compared the explanatory power of two sets of variables in the same corpus: those predicting schwa alternation and those predicting schwa duration. As we argued in Sec. I, if the absence of schwa is the end point of reduction or the result of extreme phonetic shortening, schwa alternation and schwa duration should be affected by essentially the same sets of predictors. Since vowel duration results from phonetic implementation, schwa alternation should then also result from phonetic implementation. If, in contrast, the two sets of predictors are different, schwa alternation is more likely to arise at a different, that is, higher, processing level (phonological encoding or lexical retrieval).

Table V summarizes the variables that condition schwa alternation and duration. Variables that condition both are written in italics. As we can see, the alternation between variants with and without schwa and the duration of schwa share sensitivity to speech rate and schwa position in the word. This does not necessarily mean that alternation and duration are driven by the same processes since these variables may affect speech production simultaneously at different processing levels. For instance, speech rate may affect processes at the level of phonetic implementation (e.g., Fosler-Lussier and Morgan, 1999; Kuperman et al., 2007), phonological encoding (Levelt, 1989), and lexeme retrieval (Levelt, 1989). Similarly, different processing stages may be sensitive to prosodic variables (e.g., Klatt, 1976; Oller, 1973; Warner et al., 2001).

More informative are the differences between the sets of predictors for schwa alternation and schwa duration. The three variables that only condition schwa duration have been shown to affect phonetic processes in other languages, which is in line with the hypothesis that variation in the duration of schwa results from phonetic implementation. The first variable is the word's predictability, a measure known to influence gradient segment reduction in languages such as English, Dutch, and French (e.g., Bell et al., 2003; Pluymaekers et al., 2005; Torreira and Ernestus, 2009). The second and third variables concern the voicing specifications of the consonants following and preceding the vowel. These variables have been shown to affect vowel duration in French (Di Cristo, 1985;

TABLE V. Significant predictors for schwa alternation and duration.

\begin{tabular}{ll}
\hline \hline Predictors of Schwa Alternation & Predictors of Schwa Duration \\
\hline Speech rate & Speech rate \\
Schwa position in word & Schwa position in word \\
Word position in utterance & Following consonant voicing \\
Number of consonants in sequence & Preceding consonant voicing \\
Respect of the sonority principle & Back mutual information \\
\hline \hline
\end{tabular}

O'shaughnessy, 1981) and their influence is physiologically conditioned (Delattre, 1959). Schwa alternation, in contrast, is affected by three factors that are prosodic in nature. The first predictor is position in the utterance. Variants with schwa are more frequent in utterance initial position, a position which often carries a rhythmic initial accent especially in a journalistic style of speech (as in our corpus, Vaissière, 1975). The realization of this pitch accent requires the presence of the vowel, and therefore the variant with schwa has to be selected before phonetic implementation. The second and third predictors are related to syllable well-formedness. Schwa is more often present in words where its absence would result in a two-consonant sequence with decreasing sonority. While one could always argue that these constraints are phonetically grounded (e.g., they favor ease of articulation), they are language specific (some languages like Berber have long consonant-only words which speakers utter without difficulty) and speaker specific (some speakers are not sensitive to the sonority variable). Since the duration of schwa is not affected by these variables, one can argue that the selection of the form to be pronounced occurs before phonetic implementation, be it at the lexical level (selection of the form with schwa) or during the phonological encoding of the word.

Overall, this comparison between the two sets of variables suggests different loci for schwa alternation and duration. We therefore conclude that the data in Table $\mathrm{V}$ indicate that schwa alternation is driven by lexical or phonological processes, as usually posited in phonological theories.

At first sight, this conclusion appears to be falsified by the finding of Racine and Grosjean (2002) — a finding that we replicated in the present study-that schwa is shorter if it occurs in a word which is more often produced in its variant without schwa. However, this finding can be explained by assuming that both pronunciation variants of a word (i.e., with and without schwa) are stored in the mental lexicon (as proposed in Bürki et al., 2010) and that the acoustic realization of one pronunciation variant is affected by the other variant by means of analogy. The more frequent the variant without schwa, the higher its activation level, and the more it affects the acoustic realization of the variant with schwa, leading to a shorter duration of this schwa. This explanation is in line with the hypothesis of interparadigmatic analogical effects formulated by Ernestus and Baayen (2007).

Overall, our results thus support the view that schwa alternation arises before phonetic implementation. As such, they are in line with-and thus provide some empirical evidence in favor of - the widely held theoretical assumption that schwa alternation is governed by a phonological rule. More importantly, they are also in line with recent on-line experimental evidence which suggests that the alternation arises during lexeme retrieval (Bürki et al., 2010). This convergence of experimental and corpus data makes it unlikely that the absence of schwa is simply the extreme result of the phonetic process of vowel shortening as proposed by Barnes and Kavitskaya (2002) or Smorodinsky (1988).

Our results also show the limits of corpus data for psycholinguistic research questions. First, even though our corpus data provide a strong indication that the locus of schwa alternation is not at the same level as the process governing 
schwa duration, they are not unequivocal. Since natural data are inherently noisy, we may also expect some differences between the two sets of variables, if schwa duration and alternation were to result from the same process. Second, our data do not allow us to determine the exact higher processing level at which schwa alternation occurs; they do not distinguish between a phonological and a lexical account.

In summary, the present study has identified the major predictors of French schwa alternation and schwa duration, on the basis of a comprehensive analysis of a large corpus of radio-broadcasted speech. Phonological and psycholinguistic accounts of schwa alternation have to take these variables into account and speech recognition systems, and text-tospeech synthesis systems may be improved considerably if they incorporate these variables. Furthermore, our data provide information about the locus of French schwa alternation in the human production system, which is in agreement with on-line evidence from psycholinguistic experimental studies. This convergence suggests that corpus studies can provide information that goes beyond a description of the speech produced. However, our corpus data have clear limits and show that psycholinguistic questions cannot be resolved solely on the basis of corpus studies. We conclude that corpus studies can provide relevant psycholinguistic information and should supplement on-line experiments in the study of cognitive processes underlying speech production.

\section{ACKNOWLEDGMENTS}

The authors wish to thank Ann Travis for her careful proofreading of the manuscript, and the participants who took part in the morphology test. The second author was funded by a European Young Investigator award. In addition, this work was supported by the Marie Curie Research Training Network Sound to Sense.

${ }^{1}$ Note that this classification was based on how the consonant is produced in the variant with schwa. Possible assimilation processes in variants without schwa were thus not taken into account.

${ }^{2}$ Some interactions could not be tested due to lack of observations for some levels of the factors. For example, due to phonotactic restrictions in French, some combinations of the following consonant articulation mode and the preceding consonant articulation mode do not exist in schwa words.

Adda-Decker, M. (2007). "Problèmes posés par le schwa en reconnaissance et en alignement automatiques de la parole (Problems caused by schwa in automatic speech recognition and alignment)," in Proceedings of Journées d'Études Linguistiques-2007, Nantes, France, pp. 211-216.

Adda-Decker, M., Gendrot, C., and Nguyen, N. (2008). "Contributions du traitement automatique de la parole à l'étude des voyelles orales du français (Contributions of automatic speech processing to the study of French oral vowels)," Trait. Automatique Langues 49, 13-46.

Baayen, R. H., Davidson, D. J., and Bates, D. M. (2008). "Mixed effects modeling with crossed random effects for subjects and items," J. Mem. Lang. 59, 390-412.

Bagou, O., Michel, V., and Laganaro, M. (2009). "On the production of sandhi phenomena in French: Psycholinguistic and acoustic data," in Proceedings of Interspeech-2009, Brighton, U.K, pp. 452-455.

Barnes, J., and Kavitskaya, D. (2002). "Phonetic analogy and schwa deletion in French," Berkeley Linguis. Soc. 28, 39-50.

Bates, D. M., and Sarkar, D. (2007). "Ime4: Linear mixed-effects models using S4 classes," R package version 2.6.

Bell, A., Jurafsky, D., Fosler-Lussier, E., Girand, G., Gregory, M., and Gildea, D. (2003). "Effects of disfluencies, predictability, and utterance position on word form variation in English conversation," J. Acoust. Soc. Am. 113, 1001-1024.

Bell, A., Brenier, J., Gregory, M., Girand, C., and Jurafsky, D. (2009). "Predictability effects on durations of content and function words in conversational English," J. Mem. Lang. 60, 92-111.

Boula de Mareuil, P. (2007). "Traitement du schwa: De la synthèse à l'alignement automatique (The processing of schwa: From text-to-speech synthesis to automatic alignment)," in Proceedings of Journées d'Études Linguistiques-2007, Nantes, France, pp. 181-189.

Boula de Mareüil, P., and Adda-Decker, M. (2002). "Studying pronunciation variants in French by using alignment techniques," in Proceedings of Interspeech-2002, Denver, CO, pp. 2273-2276.

Boula de Mareüil, P., Yvon, F., d'Alessandro, C., Auberge, V., Vaissière, J., and Amelot, A. (2000). "A French phonetic lexicon with variants for speech and language processing," in Proceedings of the International Conference on Language Resources and Evaluation-2000, Athena, Greece, pp. 273-276.

Browman, C. P., and Goldstein, L. (1992). "Articulatory phonology: An overview," Phonetica 49, 155-180.

Bürki, A., Ernestus, M., and Frauenfelder, U. H. (2010). "Is there only one 'fenêtre' in the production lexicon? On-line evidence on the nature of phonological representations of pronunciation variants for French schwa words," J. Mem. Lang. 62, 421-437.

Bürki, A., Gendrot, C., Gravier, G., Linares, G., and Fougeron, C. (2008). "Alignement automatique et analyse phonétique: Comparaison de différents systèmes pour l'analyse du schwa (Automatic speech alignment and phonetic analysis: A comparison of different systems for the analysis of schwa)," Trait. Automatique Langues 49, 165-197.

Bybee, J. (2001). Phonology and Language Use (Cambridge University Press, Cambridge, U.K.), 260 pp.

Cohen, J. (1968). "Weighted kappa: Nominal scale agreement with provision for scaled disagreement or partial credit," Psychol. Bull. 70, 213-220.

Charette, M. (1991). Conditions on Phonological Government (Cambridge University Press, Cambridge, U.K.), 232 pp.

Clements, G. N. (1990). "The role of the sonority cycle in core syllabification," in Between the Grammar and Physics of Speech, edited by J. Kingston and M. E. Beckman (Cambridge University Press, Cambridge, U.K.), pp. 283-333.

Content, A., Mousty, P., and Radeau, M. (1990). "Brulex, une base de données lexicales informatisée pour le français écrit et parlé (Brulex: A computerized lexical database for written and spoken French)," Année Psychol. 90, 551-566.

Côté, M.-H. (2000). Consonant Cluster Phonotactics: A Perceptual Approach, Ph.D. dissertation, Massachusetts Institute of Technology, Cambridge, MA, $367 \mathrm{pp}$.

Côté, M.-H. (2004). "Consonant cluster simplification in Québec French," Probus 16, 151-201.

Côté, M.-H. (2008). "Empty elements in schwa, liaison and h-aspiré: The French Holy Trinity reconsidered," in Sounds of Silence: Empty Elements in Syntax and Phonology, edited by J. M. Hartmann, V. Hegedüs, and H. van Riemsdijk (Elsevier, Oxford, U.K.), pp. 61-103.

Côté M.-H. (2009). "Contraintes segmentales et variation dans la perte et la stabilisation du schwa en syllabe initial (Segmental constraints and variation in the loss and stabilization of schwa in initial syllables)," in Le Français d'un Continent à l'Autre, edited by Luc Baronian and France Martineau (Presses de l'Université Laval, Quebec, Canada), pp. 93-121.

Côté M.-H., and Morrison, G. S. (2007). "The nature of the schwa/zero alternation in French clitics: Experimental and non-experimental evidence," J. French Lang. Studies 17, 159-186.

Crompton, A. (1980). "Timing patterns in French," Phonetica 37, 205-234.

Crouzet, O. (2000). "Segmentation de la parole en mots et régularités phonotactiques: Effets phonologiques, probabilistes ou lexicaux ? (Speech segmentation and phonotactic regularities: Phonological, probabilistic or lexical effects?)," Ph.D. dissertation, Université Paris 5, France, 310 pp.

Crystal, T. H., and House, A. S. (1990). "Articulation rate and the duration of syllables and stress groups in connected speech," J. Acoust. Soc. Am. 88, 101-112.

Delattre, P. (1959). "Rapports entre la durée vocalique, le timbre et la structure syllabique en français (Relationships between vowel duration, spectral quality, and syllabic structure in French)," French Rev. 32, $547-552$.

Delattre, P. (1962). "Some factors of vowel duration and their crosslinguistic validity,” J. Acoust. Soc. Am. 34, 1141-1143. 
Delattre, P. (1964). "Comparing the vocalic features of English, German, Spanish and French," Int. Rev. Appl. Lang. 2, 71-97.

Dell, F. (1985). Les Règles et Les Sons (Rules and sounds) (Hermann, Paris), 297 pp.

Di Cristo, A. (1985). De la Microprosodie à l'Intonosyntaxe (From Microprosody to Intonosyntax) (Publications de l'Université de Provence, Aixen-Provence, France), 854 pp.

Durand, J., and Eychenne, J. (2004). "Le schwa en français, pourquoi des corpus? (Schwa in French, why use corpora?)," Corpus 3, 311-356.

Ernestus, M., and Baayen, R. H. (2007). "The comprehension of acoustically reduced morphologically complex words: The roles of deletion, duration and frequency of occurrence," in Proceedings of the International Congress of Phonetic Sciences-2007, Saarbrücken, Germany, pp. 773-776.

Eychenne, J. (2006). Aspects de la Phonologie du Schwa Dans le Français Contemporain. Optimalité, Visibilité Prosodique, Gradience (Some Aspects of French Schwa Phonology in Contemporary French: Optimality, Prosodic Visibility, and Gradience), Ph.D. dissertation, Université de Toulouse-Le Mirail, France, 399 pp.

Fosler-Lussier, E., and Morgan, N. (1999). "Effects of speaking rate and word frequency on pronunciations in conversational speech," Speech Commun. 29, 137-158.

Fouché, P. (1959). Traité de Prononciation Française (Treatise on French Pronunciation) (Klincksieck, Paris), 528 pp.

Fougeron, C., Goldman, J.-P., and Frauenfelder, U. H. (2001). "Liaison and schwa deletion in French: An effect of lexical frequency and competition?" in Proceedings of Eurospeech-2001, Aalborg, Denmark, pp. 639-642.

Galliano, S., Geoffrois, E., Mostefa, D., Choukri, K., Bonastre, J.-F., and Gravier, G. (2005). "ESTER phase II evaluation campaign for the rich transcription of French broadcast news," in Proceedings of Interspeech2005, Lisboa, Portugal, pp. 1149-1152.

Goldinger, S. D. (1998). "Echoes of echoes? An episodic theory of lexical access," Psychol. Rev. 105, 251-279.

Gopal, H. (1990). "Effects of speaking rate on the behavior of tense and lax vowel duration," J. Phonetics 18, 497-518.

Grammont, M. (1914). Traité Pratique de Prononciation Française (Practical Treatise on French Pronunciation) (Delagrave, Paris), $236 \mathrm{pp}$.

Hansen, A. B. (1994). "Etude du E caduc - stabilisation en cours et variations lexicales (The study of caduc-E, stabilization in progress and lexical variations)," J. French Lang. Studies 4, 25-54.

Hay, J. (2003). Causes and Consequences of Word Structure (Routledge, New York), $237 \mathrm{pp}$

Hawkins, S. (2003). "Roles and representations of systematic fine phonetic detail in speech understanding," J. Phonetics 31, 373-405.

Jurafsky, D., Bell, A., Gregory, M., and Raymond, W. D. (2001). "Probabilistic relations between words: Evidence from reduction in lexical production," in Frequency and the Emergence of Linguistic Structure, edited by J. Bybee and P. Hopper (John Benjamins, Amsterdam), pp. 229-254.

Keating, P. (1998). "Word-level phonetic variation in large speech corpora," in ZAS Papers in Linguistics 11, edited by A. Alexiadou, N. Fuhrhop, U. Kleinhenz, and P. Law (Zentrum für Allgemeine Sprachwissenschaft, Typologie und Universalienforschung, Berlin), pp. 35-50.

Klatt, D. (1975). "Vowel lengthening is syntactically determined in a connected discourse," J. Phonetics 3, 129-140.

Klatt, D. (1976). "Linguistic uses of segmental duration in English: Acoustic and perceptual evidence," J. Acoust. Soc. Am. 59, 1208-1221. Kuperman, V., Pluymaekers, M., Ernestus, M., and Baayen, H. (2007). "Morphological predictability and acoustic duration of interfixes in Dutch compounds," J. Acoust. Soc. Am. 121, 2261-2271.

Lanchantin, P., Morris, A., Rodet, X., and Veaux, C. (2008). "Automatic phoneme segmentation with relaxed textual constraints," in Proceedings of the International Conference on Language Resources and Evaluation 2008, Marrakech, Morocco, pp. 2403-2407.

Landis, J., and Koch, G. (1967). "The measurement of observer agreement for categorical data," Biometrics 33, 159-174.

Léon, P. (1971). Essai de Phonostylistique (Essay on Phonostylistic) (Didier, Ottawa), 185 pp.

Léon, P. (2005). Phonétisme et Prononciations du Français (French Phonetics and Pronunciation) (Armand Colin, Paris), 192 pp.
Léon, P., and Tennant, J. (1988). "Observations sur la variation morphophonologique et phonématique dans Apostrophe (Observations on morphophonological and phonetic variation in Apostrophe)," Toronto Working Pap. 9, 20-47.

Levelt, W. J. M. (1989). Speaking: From Intention to Articulation (MIT Press, Cambridge, U.K.), 566 pp.

Lyche, C., and Durand, J. (1996). "Testing government phonology ou pourquoi le choix du schwa ?," in Current Trends in Phonology: Models and Methods, edited by J. Durand and B. Laks (European Studies Research Institute, Salford), pp. 443-471.

Malécot, A. (1976). "The effect of linguistic and paralinguistic variables on the elision of the French mute-e," Phonetica 33, 93-112.

Malécot, A. (1977). Introduction à la Phonétique Française (An Introduction to French Phonetics) (Mouton, Hague, Netherlands), 68 pp.

New, B., Pallier, C., Ferrand, L., and Matos, R. (2001). "Une base de données lexicales du français contemporain sur internet: LEXIQUE (A lexical database of contemporary French on the internet: LEXIQUE)," L'Année Psychol. 101, 447-462.

Oller, D. K. (1973). "The effect of position in utterance on speech segment duration in English," J. Acoust. Soc. Am. 54, 1235-1247.

O'Shaughnessy, D. (1981). "A study of French vowel and consonant durations," J. Phonetics 9, 385-406.

Pierrehumbert, J. (2001). "Exemplar dynamics: Word frequency, lenition, contrast," in Frequency and the Emergence of Linguistic Structure, edited by J. Bybee and P. Hopper (John Benjamins, Amsterdam), pp. 137-157.

Pinheiro, J. C., and Bates, D. M. (2000). Mixed-Effects Models in S and SPLUS (Springer, New York), 528 pp.

Pluymaekers, M., Ernestus, M., and Baayen, R. H. (2005). "Lexical frequency and acoustic reduction in spoken Dutch," J. Acoust. Soc. Am. 118, 2561-2569.

R Development Core Team (2011). "R: A language and environment for statistical computing," R Foundation for Statistical Computing, Vienna, Austria, available at http://www.R-project.org.

Racine, I. (2007). "Effacement du schwa dans des mots lexicaux: Constitution d'une base de données et analyse comparative (Schwa deletion in lexical words: The construction of a lexical database and comparative analysis)," in Proceedings of Journées d'Études Linguistiques-2007, Nantes, France, pp. 125-130.

Racine, I., and Grosjean, F. (2002). "La production du E caduc facultatif est-elle prévisible? Un début de réponse (Is the production of the optional E predictable? The beginnings of a reply)," J. French Lang. Studies 12, 307-326.

Ranbom, L. J., and Connine, C. M. (2007). "Lexical representation of phonological variation in spoken word recognition”, J. Mem. Lang. 57, 273-298.

Scarborough, R. (2010). "Lexical and contextual predictability: Confluent effects on the production of vowels," in Papers in Laboratory Phonology $X$, (Mouton de Gruyter, Hague, Netherlands), pp. 557-586.

Smorodinsky, I. (1998). "The phonology and phonetics of schwa in Parisian French: An articulatory analysis," Texas Linguis. Forum 41, $161-171$.

Strik, H., and Cucchiarini, C. (1999). "Modeling pronunciation variation for ASR: A survey of the literature," Speech Commun. 29, 225-246.

Thilly, C. (1993). "Influence of prevocalic consonant on vowel duration in French CV[p] utterances," in Proceedings of Eurospeech-1993, Berlin, Germany, pp. 465-468.

Torreira, F., and Ernestus, M. (2009). "Probabilistic effects on French [t] duration," in Proceedings of Interspeech-2009, Brighton, U.K., pp. 448-451.

Vaissière, J. (1975). "Further note on French prosody," Quarterly Progress Report, Research Laboratory of Electronics, Massachusetts Institute of Technology 115, 251-261.

Van Bael, C., Baayen, H., and Strik, H. (2007). "Segment deletion in spontaneous speech: A corpus study using mixed effects models with crossed random effects," in Proceedings of Interspeech-2007, Antwerp, Belgium, pp. 2741-2744.

Walker, D. C. (1996). "The new stability of unstable-e in French,” J. French Lang. Studies 6, 211-229.

Warner, N., Jongman, A., Cutler, A., and Mücke, D. (2001). "The phonological status of Dutch epenthetic schwa," Phonology 18, 387-420.

Wrede, B. (2002). Modeling the Effects of Speech Rate Variation for Automatic Speech Recognition, Ph.D. dissertation, Publications at Bielefeld University, Bielefeld, Germany, $121 \mathrm{pp}$. 